\title{
The Characterization of Linear Polyethylene SRM 1475. III. Density Determination
}

\author{
James E. Brown \\ Institute for Materials Research, National Bureau of Standards, Washington, D.C. 20234
}

(December 15, 1971)

\begin{abstract}
The density of SRM 1475 at $23^{\circ} \mathrm{C}$ was determined by ASTM method D 1505-67 on samples prepared by Procedure A of ASTM method D 1928-68, with the result $0.9784 \mathrm{~g} / \mathrm{cm}^{3}$.
\end{abstract}

Key words: Crystallization; degree of crystallinity; density; linear polyethylene; polymer; recrystallization.

\section{Introduction}

The density of polyethylene crystallized from its melt is sensitive to a number of factors which influence the degree of crystallinity. Among these factors are: the polymer's previous thermal history and crystallization temperature which affect the perfection and rate of crystal growth $[1-4],{ }^{1}$ the average molecular weight and its distribution [3], and the amount of branching [5-6].

In this paper we report the results of the density measurements on linear polyethylene SRM 1475. The density measurements and the sample preparation were performed using standard methods of the American Society for Testing and Materials (ASTM). It was necessary to specify closely the preparation of the samples used in this determination since the density of polyethylene depends to such an important extent on the polymer's previous history. From our experience, it should be possible to duplicate these results closely provided that the same methods are followed.

\section{Experimental Procedure}

Three composite samples, weighing about $100 \mathrm{~g}$ each, were made up separately as described in the first paper of this series [7] by blending equal amounts of the SRM 1475 pellets taken from the tops and bottoms of each of the original containers. These three composite samples will subsequently be referred to as blend I, II, and III.

Test samples (plaques) were prepared from blend I by Procedure A of ASTM Designation: D 1928-68, "Standard Method for Preparation of CompressionMolded Polyethylene Test Samples." 2 In accordance with this procedure, the pellets of blend I were made

\footnotetext{
${ }^{1}$ Figures in brackets indicate the literature references at the end of this paper. ${ }^{2}$ Available from the American Society for Testing and Materials, 1916 Race Street, Philadelphia, Pennsylvania 19103
}

into a crepe on a roll mill. The polyethylene was milled for about four minutes at a temperature sufficiently high to cause the polymer to flux but not to drip. Pieces were cut from the cooled crepe and compression molded into $3 \mathrm{~mm}$ thick plaques at $178{ }^{\circ} \mathrm{C}$ using picture-frame-like chases. ${ }^{3}$ The mold assembly containing the molten polyethylene was removed from the press and quenched to room temperature in a water bath. The mold assemblies containing the quenched plaques were then placed in a heated oven and maintained at $170{ }^{\circ} \mathrm{C}$, well above the crystal melting point, for $1 \mathrm{~h}$ or more in order to destroy the polymer's previous thermal history. The temperature of the oven was then lowered to $50{ }^{\circ} \mathrm{C}$ at a rate of $5{ }^{\circ} \mathrm{C} / \mathrm{hr}$. After the plaques had come to room temperature, several specimens (2-3 $\mathrm{mm}$ on a side) were cut from each plaque for the density measurements.

As a check on the sensitivity of the ASTM procedure to variations in the preparative technique, plaques of blends II and III were prepared somewhat differently. Plaques of blend II were prepared as described above except that the milling time (about 2 minutes) was just long enough at about $125{ }^{\circ} \mathrm{C}$ to cause the pellets to fuse into a sheet. The plaques of blend III were not molded from a milled crepe. These plaques were compression-molded from the pellets. Except for the milling process, the test samples (plaques) of blend III were quenched, recrystallized, and cooled to room temperature by the same techniques described for blends I and II.

The density of the three blends was determined by the procedure given in ASTM Designation: D1505-67, "Standard Method of Test for Density of Plastics by the Density-Gradient Technique." ${ }_{2}$ The density of each specimen taken from the recrystallized plaques was determined by graphical interpolation of its equilibrium height in the density-gradient liquid

${ }^{3}$ Although paragraph 5.6 of the ASTM procedure calls for a preheating period of $5 \mathrm{~min}$, we have employed a time of $15 \mathrm{~s}$. 
maintained at $23 \pm 0.1{ }^{\circ} \mathrm{C}$. Isopropanol and water were used as the density-gradient liquids. The column was calibrated by a series of glass beads whose density was known to within $\pm 0.0001 \mathrm{~g} / \mathrm{cm}^{3}$. The sensitivity of the column was found to be about $0.0002 \mathrm{~g} / \mathrm{cm}^{3}$ per $\mathrm{mm}$ column height, and the position of beads and specimens could be read to about $1 \mathrm{~mm}$.

\section{Results and Discussion}

The molding and recrystallization of the plaques and the density measurements were performed on several different days according to ASTM procedures for sample preparation and density measurement. No significant day-to-day variation was found in the results. It was concluded that the preparation and recrystallization of the samples were consistent from one experiment to the next to within the precision of the density determination. The average density of twelve specimens taken from five samples (plaques) of blend I was found to be $0.97844 \mathrm{~g} / \mathrm{cm}^{3}$ with a sample standard deviation of a single determination of 0.00014 $\mathrm{g} / \mathrm{cm}^{3}$. The sample standard deviation of the mean of the twelve determinations is therefore $0.00004 \mathrm{~g} / \mathrm{cm}^{3}$. These values of the mean density and the sample standard deviation of the mean are reported on the certificate for SRM 1475. The range of the measurements was from 0.9784 to $0.9786 \mathrm{~g} / \mathrm{cm}^{3}$.

The average of ten density measurements on blend II was found to be $0.97817 \mathrm{~g} / \mathrm{cm}^{3}$ with a standard deviation of a single determination of $0.00010 \mathrm{~g} / \mathrm{cm}^{3}$. The density measurements for blend III gave a result of $0.97493 \mathrm{~g} / \mathrm{cm}^{3}$ with a standard deviation of a single measurement of $0.00045 \mathrm{~g} / \mathrm{cm}^{3}$, based on 21 measurements. These results are summarized in table 1 . From the sample standard deviations and the systematic uncertainties associated with the calibrating beads,

Table 1. Density at $23^{\circ} \mathrm{C}$ of Linear Polyethylene SRM 1475

\begin{tabular}{|c|c|c|c|}
\hline & Blend I & Blend II & Blend III \\
\hline Average density, $\mathrm{g} / \mathrm{cm}^{3}$. & $* 0.97844$ & 0.97817 & 0.97493 \\
\hline $\begin{array}{c}\text { Standard deviation of a single } \\
\text { measurement.......................... }\end{array}$ & 0.00014 & 0.00010 & 0.00045 \\
\hline 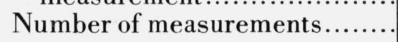 & 12 & 10 & 21 \\
\hline
\end{tabular}

* Certificate value.

The samples of blend I were prepared from pellets of polyethylene which had been fluxed and milled twice as long (about 4 minutes) as blend II. The samples of blend III were molded from the polyethylene pellets. we conclude that the overall accuracy of our measurements is well within the 0.05 percent limit cited in the ASTM procedure.

Although the 0.03 percent difference between the densities of blends I and II is statistically significant, for practical purposes this difference is unimportant in view of the 0.05 percent estimate of accuracy given in the ASTM procedure. On the other hand, the density of blend III (unmilled samples) is materially lower than that of blends I and II, and its standard deviation of a single measurement is much larger than those of blends I and II. These differences cannot be ascribed to differences in the crystallinity of the samples, for the parts of the procedure which might be expected to affect crystallinity (molding, quenching, recrystallization) were identical for all three blends. Nor can the differences be attributed to the lack of mixing of the individual pellets during the preparation of blend III, since pellet-to-pellet variation would be expected to yield a larger sample standard deviation for blend III than for blends I and II, but the same mean density. The most likely explanation of both the lower mean density of blend III and its larger sample standard deviation seems to be the presence of small voids resulting from the lack of milling and fluxing. This explanation is reinforced by the fact that specimens taken from plaques of blend III, even though carefully selected, appeared to contain small regions of entrapped air.

We conclude that the preparatory milling and fluxing stipulated in the ASTM procedure is essential if the stated precision of the procedure is to be realized.

\section{References}

[1] Mandelkern, L., in Growth and Perfection of Crystals, Ed. R. H. Doremus, B. W. Roberts, and D. Turnbull, p. 467 (John Wiley and Sons, Inc., New York, N.Y., 1958).

[2] Mandelkern, L., Posner, A. S., Diorio, A. F., and Roberts, D. E., J. Appl. Phys. 32, 1509 (1961).

[3] Chiang, R. and Flory, P., J. Am. Chem. Soc. 83, 2857 (1961).

[4] Weeks, J. J., Jr., J. Res. Nat. Bur. Stand. (U.S.), 67A (Phys. and Chem.), No. 5, 441-45l (Sept.-Oct. 1963).

[5] Stella, C., Compt. Rend. 248, 1819 (1959).

[6] Sperati, C. A., Franta, W. G., and Starkweather, H. W., Jr., J. Am. Chem. Soc. 75, 6157 (1953).

[7] Hoeve, C. A. J., Wagner, H. L., and Verdier, P. H., J. Res. Nat. Bur. Stand. (U.S.), 76A (Phys. and Chem.), No. 2, 137-140 (Mar.-Apr. 1972). Paper I of this series.

(Paper 76A2-708) 